\section{Broadening Participation in the Life Sciences: Current Landscape and Future Directions}

\section{Kenneth D. Gibbs, Jr. ${ }^{+*}$, and Pat Marsteller}

tOffice of Program Planning, Analysis and Evaluation, National Institute of General Medical

Sciences, Bethesda, MD 20892; :Department of Biology, Emory University, Atlanta, GA 30322

"B roadening participation" and related terms such as "diversity," "inclusion," and "equity" mean many things to different people. For this special issue, we defined the term "broadening participation" to mean efforts that develop talent and promote the inclusion of students and scientists from all social backgrounds in all levels of the life sciences (K-12 through postdoctoral training, early-career independence, and senior leadership). The topic of broadening participation is often accompanied by controversy and concerns about nonmeritocratic decision making and the diminution of quality and rigor. It is our vision that the results of broadening participation efforts would be a vibrant scientific enterprise that continues to harness the contributions of those from traditionally well-represented backgrounds while fostering full participation and engagement of those from other backgrounds (e.g., women, racial and ethnic minorities, people with disabilities, sexual and gender minorities, first-generation students, those from low-income backgrounds).

Over the past few decades, the life sciences have made significant progress in increasing the participation in education of women and students from historically underrepresented racial and ethnic minority backgrounds (URM, i.e., African American, Hispanic/Latino, American Indian, Alaska Native, Native Hawaiian and Pacific Islander; National Science Foundation, National Center for Science and Engineering Statistics, 2015). In 2012, women earned more than 50\% of bachelor's degrees and PhDs in the life sciences. Students from URM backgrounds earned $17 \%$ of bachelor's degrees and $8 \%$ of PhDs (which, while lower than their $32 \%$ representation in the population, represents progress). At the same time, there is significant evidence that students from these groups continue to face challenges within the classroom and training environments (Gibbs and Griffin, 2013; Eddy et al., 2014; Grunspan et al., 2016; Lauer et al., 2016). Women and scientists from URM backgrounds remain underrepresented as principal investigators on research grants, as faculty members, and in senior leadership positions (Myers and Fealing, 2012; National Institutes of Health, 2012; Heggeness et al., 2016; Plank-Bazinet et al., 2016). Other groups, such as Asian-American scientists, are often well represented in undergraduate and graduate programs and in junior faculty positions (though there are differences across ethnicity), yet still experience stereotyping and remain underrepresented in senior leadership positions (Maramba et al., 2014). These and other representation gaps lead to the loss of contributors to the talent pool and limit the ability of the life sciences community to address critical scientific and societal challenges (Tabak and Collins, 2011; Ferrini-Mundy, 2013; Valantine and Collins, 2015).

Clearly, we are not the only ones who recognize the persistent issue of limited participation in the life sciences. We received more than 120 submissions in response to our initial call for abstracts for this special issue, and 57 submissions of full manuscripts. (For context, CBE—Life Sciences Education received 194 submissions in all of 2015.) The papers published in this issue fit four main themes:
CBE Life Sci Educ September 1, 2016 15:ed1 DOI:10.1187/cbe.16-06-0198

*Address correspondence to: Kenneth D. Gibbs, Jr. (kenneth.gibbs@nih.gov).

(c) 2016 K. D. Gibbs and P. Marsteller. CBE-Life Sciences Education () 2016 The American Society for Cell Biology. This article is distributed by The American Society for Cell Biology under license from the author(s). It is available to the public under an Attribution-Noncommercial-Share Alike 3.0 Unported Creative Commons License (http://creativecommons.org/licenses/ by-nc-sa/3.0).

"ASCB®" and "The American Society for Cell Biology $\AA^{\prime \prime}$ are registered trademarks of The American Society for Cell Biology. 
- Innovative and effective interventions or approaches for broadening participation,

- Mechanistic explanations for "why" certain approaches have been effective,

- Novel insights about contextual issues that influence broadening participation efforts, and

- Syntheses of research and practices that provide a "plan of action" heading forward.

We also invited features from major life sciences education funding agencies (National Institutes of Health, National Science Foundation, U.S. Department of Agriculture, and Howard Hughes Medical Institute) that highlight current funding opportunities and provide perspectives on challenges and opportunities related to broadening participation in the life sciences.

As the life sciences community continues its efforts to broaden participation, we feel it is important to take the following approaches:

Clearly define benchmarks of success and associated measures. Broadening participation research and evaluation efforts can be impaired by a lack of clearly defined variables, desired outcomes, or common language. For example, terms like "retention" or "persistence" are not self-evident. Retained for what? Persisted to what? Similarly, people often identify as having multiple, intersecting social identities that interact to effect experiences and outcomes (Griffin and Museus, 2011). Thus, care must be used when applying demographic labels such that it is clear what populations are impacted by the approach. Future research and evaluation efforts should clearly define:

- Who is (are) the intended target population(s)? This requires more nuanced language such that our data and analyses can be more nuanced. For example, a first-generation immigrant from Laos and a fourth-generation Japanese-American may both be identified as "Asian" but are likely to have substantively different experiences in life sciences education and career development.

- What are the desired outcomes, and why are they important for the intended target population(s)? This requires assessment of the context in which an intervention is to be deployed to ensure it is necessary and to provide a baseline against which to test the effectiveness of the intervention.

- Where, or in what context, are approaches being examined or tested? This requires the recognition and articulation of the unique opportunities and constraints imposed by the environment. An intervention that is successful in one context (e.g., a 2-year institution) may or may not have the same impact in a different context (e.g., an academic medical center).

- What is the theoretical or empirical work that supports the potential for the intervention to be successful? There are many, validated theoretical approaches for examining factors that impact broadening participation efforts, ranging from classroom learning to career choice (Eccles and Wigfield, 2002; Lent et al., 2002; Hurtado et al., 2012). These and other relevant frameworks should be used in formulating and framing broadening participation efforts.

- How will we know whether we are successful? Interventions targeted at outcomes such as learning gains or enhancing entry or transition into the next training or career stage should measure these outcomes as directly as possible.
Institutionalize the collection, analysis, and reporting of relevant participation data, and use them in decision making. Systematic data collection and analysis efforts will require institutional commitment at all levels, including administrators, faculty members, and staff. Tools are being developed that can help accomplish this, such as Tools for Evidence-based Action (http://t4eba.com) at the University of California-Davis. The community must consider which metrics and metadata are most informative and how they can be standardized in ways that maintain their usefulness both locally and nationally. Acting on this recommendation will require not only collecting data but also reporting them to people in positions to take action. For example, disaggregated data on student flow and success must be shared with faculty and staff in ways that protect student and colleague confidentiality. Faculty and staff must also be empowered and incentivized to use the data to identify issues, formulate plans, take actions, and evaluate progress.

Take a systemic approach to broadening participation. Our view is that the persistent challenge of broadening participation results from the complex interplay of individual, contextual (e.g., in the classroom, research group, or department), institutional, and systemic factors. To meaningfully "move the needle" on outcomes requires understanding how these factors interact and intervening across them. For example, programs aimed at freshman success in "gateway" courses or providing undergraduate research experiences are important and necessary. However, if the ultimate goal of these efforts is to impact diversity at more distal endpoints (such as the professoriate), they must be coupled with strategies that address the entire career development pathway, including doctoral education, postdoctoral training, faculty appointments, grant making, and promotion and tenure criteria. Additionally, it is important to consider the extent to which traditional measures of merit (and the incentive structures they produce) continue to serve the life sciences community and efforts to broaden participation. For example, there is evidence that, at a population level, women and students from URM backgrounds are disproportionately motivated to pursue science because of the ability to apply scientific knowledge to real-world problems (Thoman et al., 2015; Diekman et al., 2016; Jackson et al., 2016). Therefore, continued emphasis on traditional research topics approached in traditional ways that do not emphasize or promote how scientific knowledge can be used to address practical problems may differentially impact their academic and career advancement.

Leave "the pipeline" framework behind. No metaphor is so deeply entrenched in conversations around the scientific workforce in general and diversity in particular as "the STEM pipeline." However, we firmly believe that this metaphor poorly describes the development of scientists (Cannady et al., 2014). "The pipeline" implicitly limits pathways for entry and reentry into the scientific enterprise and shifts focus away from systemic issues that differentially impact the participation of scientists from various backgrounds. We explicitly asked authors in this special issue not to use this term in their manuscripts and instead to focus on "career development pathways" or the development of the "talent pool." Metcalf's essay in this issue uses critical theory to illuminate the limitations of the pipeline metaphor and the necessity of questioning popular models of 
scientific development and retention (Metcalf, 2016). To be clear, although the term "pipeline" is problematic, we support many of programs and structures that were catalyzed by this metaphor and that have resulted in participation gains in life sciences education and career development.

Oftentimes, the case for broadening participation efforts is made for reasons that range from increasing innovation, to ensuring the United States maintains an adequate domestic talent supply in the context of changing demographics, to correcting historical injustices (Page, 2008; National Academy of Sciences, National Academy of Engineering, and Institute of Medicine, 2011). While all of these justifications are valid, our hope is that we will soon move to a world in which the opposite question is asked: Why would we not do everything we can to broaden participation? The system we have has served us well, but it needs to evolve in a manner that will serve us optimally in the future. As there is no evidence that scientific potential or ability are coupled with the social and demographic categories we use to describe ourselves, broadening participation will allow the life sciences community to cultivate and harness all available talent to identify and address pressing scientific and societal concerns.

\section{REFERENCES}

Cannady MA, Greenwald E, Harris KN (2014). Problematizing the STEM pipeline metaphor: is the STEM pipeline metaphor serving our students and the STEM workforce? Sci Educ 98, 443-460.

Diekman AB, Steinberg M, Brown ER, Belanger AL, Clark EK (2016). A goal congruity model of role entry, engagement, and exit: understanding communal goal processes in STEM gender gaps. Pers Soc Psychol Rev, doi: $10.1177 / 1088868316642141$

Eccles JS, Wigfield A (2002). Motivational beliefs, values, and goals. Annu Rev, Psychol 53, 109-132.

Eddy SL, Brownell SE, Wenderoth MP (2014). Gender gaps in achievement and participation in multiple introductory biology classrooms. CBE Life Sci Educ 13, 478-492.

Ferrini-Mundy J (2013). Science education. Driven by diversity. Science 340, 278.

Gibbs KD Jr, Griffin KA (2013). What do I want to be with my PhD? The roles of personal values and structural dynamics in shaping the career interests of recent biomedical science PhD graduates. CBE Life Sci Educ 12, 711-723.

Griffin KA, Museus S (2011). Using Mixed-Methods to Study Intersectionality in Higher Education: New Directions in Institutional Research, vol. 151, San Francisco: Jossey-Bass.

Grunspan DZ, Eddy SL, Brownell SE, Wiggins BL, Crowe AJ, Goodreau SM (2016). Males under-estimate academic performance of their female peers in undergraduate biology classrooms. PLoS One 11, e0148405.

Heggeness ML, Evans L, Pohlhaus JR, Mills SL (2016). Measuring diversity of the National Institutes of Health-funded workforce. Acad Med, doi: 10.1097/ACM.0000000000001209

Hurtado S, Alvarez CL, Guillermo-Wann C, Cuellar M, Arellano L (2012). A model for diverse learning environments. In: Higher Education: Handbook of Theory and Research, ed. JC Smart and MB Paulsen, New York: Springer, 41-122.

Jackson MC, Galvez G, Landa I, Buonora P, Thoman DB (2016). Science that matters: the importance of a cultural connection in underrepresented students' science pursuit. CBE Life Sci Educ 15, ar42.

Lauer M, Valantine H, Collins FS (2016). Policy: NIH push to stop sexual harassment. Nature 531, 35.

Lent RW, Brown SD, Hackett G (2002). Social cognitive career theory. In: Career Choice and Development, 4th ed., ed. D Brown, San Francisco: Jossey-Bass, 255-311.

Maramba DC, Pak YK, Xavier H (2014). Charting New Realities: Asian Americans in Higher Education, San Francisco: Jossey-Bass.

Metcalf $\mathrm{H}$ (2016). Broadening the study of participation in the life sciences: how critical theoretical and mixed-methodological approaches can enhance efforts to broaden participation. CBE Life Sci Educ 15, rm3.

Myers SL Jr, Fealing $\mathrm{KH}$ (2012). Changes in the representation of women and minorities in biomedical careers. Acad Med 87, 1525-1529.

National Academy of Sciences, National Academy of Engineering, and Institute of Medicine (2011). Expanding Underrepresented Minority Participation: America's Science and Technology Talent at the Crossroads, Washington, DC: National Academies Press.

National Institutes of Health (2012). Draft Report of the Advisory Committee to the Director Working Group on Diversity in the Biomedical Research Workforce. http://acd.od.nih.gov/dbr.htm (accessed 1 June 2016).

National Science Foundation, National Center for Science and Engineering Statistics (2015). Women, Minorities, and Persons with Disabilities in Science and Engineering Special Report (NSF 15-311), Arlington, VA: National Science Foundation. www.nsf.gov/statistics/2015/nsf15311 (accessed 1 June 2016)

Page SE (2008). The Difference: How the Power of Diversity Creates Better Groups, Firms, Schools, and Societies, Princeton, NJ: Princeton University Press.

Plank-Bazinet JL, Bunker Whittington K, Cassidy SK, Filart R, Cornelison TL, Begg L, Austin Clayton J (2016). Programmatic efforts at the National Institutes of Health to promote and support the careers of women in biomedical science. Acad Med, doi: 10.1097/ACM.0000000000001239.

Tabak LA, Collins FS (2011). Weaving a richer tapestry in biomedical science. Science 333, 940-941.

Thoman DB, Brown ER, Mason AZ, Harmsen AG, Smith JL (2015). The role of altruistic values in motivating underrepresented minority students for biomedicine. BioScience 65, 183-188.

Valantine HA, Collins FS (2015). National Institutes of Health addresses the science of diversity. Proc Natl Acad Sci USA 112, 12240-12242. 